\title{
Modulation of the human preadipocyte mitochondrial activity by beta-carotene*
}

\author{
Agnieszka Śliwa ${ }^{凶}$, Joanna Góralska, Urszula Czech, Anna Gruca, Anna Polus, Barbara Zapała \\ and Aldona Dembińska-Kieć
}

Department of Clinical Biochemistry, Jagiellonian University Medical College, Kraków, Poland

\begin{abstract}
Increased ROS generation by the overload by metabolic substrates mitochondria paralleled by decrease of antioxidant activity are typical events found in metabolic syndrome and diabetes type 2. Metabolites of betacarotene (BC) such as retinoic acid (RA), as well as low concentration of reactive oxygen species (ROS) modify the mitochondrial bioenergetic function. The aim of the study was to investigate the effect of beta-carotene on mitochondrial activity in human preadipocytes. BC used in concentrations, 10 or $30 \mu \mathrm{M}$, decreased mitochondrial membrane potential, inhibited mitochondrial respiration and decreased cellular ATP content. We conclude, that $\mathrm{BC}$, the known antioxidant may decrease oxidative phosphorylation capacity of mitochondria.
\end{abstract}

Key words: beta-carotene, preadipocytes, mitochondria, oxidative phosphorylation

Received: 14 October, 2011; accepted: 01 March, 2012; available on-line: 17 March, 2012

\section{INTRODUCTION}

Mitochondria play an essential role in cellular bioenergetics. Disturbances in mitochondrial metabolism play a role in aging as well as in acquired and inherited metabolic disorders (Borutaite, 2010). Abnormal mitochondrial function results in lipid droplets accumulation characteristic for insulin resistance, as cells require a balance between oxidative phosphorylation (OXPHOS) and dissipation of the proton gradient, to minimize damage of "glucolipotoxicity"-induced reactive oxygen species (ROS) generation (Bournat \& Brown, 2010). Changes in mitochondrial biogenesis and function have been documented in the diabetes and metabolic syndrome (Ren et al., 2010). Mitochondrial dysfunction in mature adipocytes has been linked to defects in fatty acid oxidation, secrection of adipokines and dysregulation of glucose homeostasis (Bournat \& Brown, 2010).

In human beta-carotene $(\mathrm{BC})$ is converted to retinoic acid (RA) which exert potent effects on cell differentiation, proliferation and fetal development (Kotake-Nara et al., 2001; Palozza et al., 2001). Several studies have proved that carotenoids may act as anti-oxidants or as pro-oxidants, depending on their concentration into the cells as well as on cell oxidative environment (Palozza, 1998). Last reports revealed that mitochondrial dysfunction leads to impaired lipid metabolism and/or oxidation of lipids, proteins, and mtDNA, which trigger the accumulation of TGs in the cytosol of preadipocytes, a process mediated through a decrease in fatty acid $\beta$-oxidation and an increase in lipogenesis (Wang et al.,
2010). Since the effect of this nutrient on metabolism of human preadipocytes is still not well recognized, this work was aimed to investigate the influence of $\mathrm{BC}$ on mitochondrial bioenergetic functions, in immortabilized human Chub-S7 preadipocytes.

\section{MATERIALS AND METHODS}

Reagents. All the reagents for cell culture were purchased from Sigma Aldrich Steinheim (Germany) unless noted otherwise.

The HPLC grade beta-carotene was kindly provided for the study by the Roche Vitamins AG, Kaiseraugust, Switzerland.

Cells culture. The Chub-S7 (Nestec Ltd) cell line was derived from human subcutaneous adipose tissue by coexpression of human telomerase reverse transcriptase and papillomavirus E7 oncoprotein (HPV-E7) genes (Darimont et al., 2003). Confluent Chub-S7 cells were cultured in DMEM/Ham's F-12 medium supplemented with 10\% Fetal bovine serum (Gibco). The cells were incubated with three different concentrations of beta-carotene $(3 \mu \mathrm{M} ; 10 \mu \mathrm{M}$ and $30 \mu \mathrm{M})$ in $5 \% \mathrm{CO}_{2}$ at $37^{\circ} \mathrm{C}$ for 24 hours. Control cells were incubated with an appropriate concentrations of solvent $(0.05 \%$ final concentration of $\mathrm{THF}$ /ethanol).

Mitochondrial membrane potential $(\Delta \Psi \mathrm{m})$. Mitochondrial membrane potential was analyzed by MitoProbe $^{\mathrm{TM}}$ JC-1 Assay Kit for flow cytometry (Molecular Probes). Mitochondrial depolarization was indicated by a decrease in the red/green fluorescence intensity ratio.

Mitochondrial respiration. The function of the respiratory transport chain was analyzed by high-resolution respirometry in Oxygraph-2k respirometer (Oroboros Instruments) according to the phosphorylation control protocol for intact cells (Garedew et al., 2010). The protocol included in sequence: (i) a 10-min period of ROUTINE respiration, reflecting the aerobic metabolic activity under cellular routine conditions (ii) the oligomycin (final concentration $2 \mu \mathrm{g} / \mathrm{ml}$ )-inhibited LEAK respiration, which is caused mainly by compensation for the proton leak after inhibition of ATP synthase; (iii) the FCCP (p-trifluoromethoxy carbonyl cyanide phenyl hydrazone) titration, which yields the maximum stimulated respiration, as a measure of electron transport system capacity

e-mail: agasliw@interia.pl

* Presented at the 16th International Symposium on Carotenoids, 17-22 July, 2011, Kraków, Poland

Abbreviations: ATP, adenosine-5'-triphosphate; $\mathrm{BC}$, beta-carotene; OXPHOS, oxidative phosphorylation; RA, retinoic acid; $R O S$, reactive oxygen species; TGs, triglycerides: $\Delta \Psi \mathrm{m}$, mitochondrial membrane potential. 
of uncoupled mitochondria. Inhibitor and the uncoupler applied in this protocol are freely permeable through the intact plasma membrane and do not require cell membrane permeabilization (Renner et al., 2003). The rates of respiration was calculated as time derivative of oxygen flux rates per million cells.

ATP assay. The intracellular ATP content was measured using ATPlite ${ }^{\mathrm{TM}}$ Luminescence ATP Detection Assay System (Perkin Elmer). Results were calculated with Magellan6 software as nmol ATP, and then adjusted for protein content (measured by Lowry method), and reported as nmolATP/mg of protein.

\section{RESULTS}

\section{Mitochondrial membrane potential $\left(\Delta \Psi_{\mathrm{m}}\right)$}

The significant decrease of $\Delta \Psi \mathrm{m}$ in Chub-S7 cells after incubation with $10 \mu \mathrm{M}$ as well as $30 \mu \mathrm{M}$ of BC was observed (Fig. 1) and the effect was stronger at the higher concentration of $\mathrm{BC}$. At the lower concentration of $\mathrm{BC}(3 \mu \mathrm{M})$ we did not observe any influence on $\Delta \Psi \mathrm{m}$ in Chub-S7 cells.

\section{Mitochondrial respiration}

A dose-dependent inhibition of routine respiration was observed after incubation of Chub-S7 cells with betacarotene (Fig. 2). At the lowest concentration $(3 \mu \mathrm{M})$ it was only tendency, when at the higher concentrations of $\mathrm{BC}$ the effect was significant. Additionally, BC (especially at $10 \mu \mathrm{M}$ concentration) reduced the oligomycin- inhibited LEAK respiration (Fig. 3), which is caused mainly by compensation for the proton leak after inhibition of ATP synthase. The maximum stimulated respiration (the measure of electron transport system capacity of uncoupled mitochondria) represent as ETS was also decreased after incubation with BC (Fig. 3).

\section{Intracellular ATP content}

Incubation with higher concentrations of BC, especially $10 \mu \mathrm{M}$, decreased the cellular ATP content (Fig. 4). After incubation with $3 \mu \mathrm{M}$ of $\mathrm{BC}$ we did not observe any significant effect.

\section{DISCUSSION}

The reported basal concentrations of beta-carotene in human serum does not exceed $1 \mu \mathrm{mol} / 1$ and BC supplementation increased it by about 10-15-fold (DembińskaKieć et al., 2005; Dulińska et al., 2005). In our experiments, we used "physiological" up to $30 \mu \mathrm{M}$ BC concentrations, which is commonly used (Dembińska-Kieć et al., 2005; Sacha et al., 2005; Kieć-Wilk et al., 2009).

Carotenoids may act as anti-oxidants or as pro-oxidants, depending on their concentration in the cells, cell type and cell oxidative environment (Palozza, 1998). High concentrations of carotenoids seem to enhance their pro-oxidant effects in biological systems (Palozza et al., 2001). Beta-carotene can induce the release of cytochrome $c$ from mitochondria and change mitochondria membrane potential in different tumor cells (Palozza et al., 2004), what is in accordance with our results showing that $\mathrm{BC}$ significantly decreases mitochondrial membrane potential in human preadipocytes.

Carotenoids may undergo oxidation and form carotenoid-derived aldehydes (CDA), which can be toxic to tissues. Kalariya et al. (2008) observed that CDA increase apoptosis in pigment epithelial cells. Early appearance of apoptotic changes in these cells were associated with change in $\Delta \Psi \mathrm{m}$. It is likely that CDA forms adducts with thiol groups of the mitochondrial proteins,

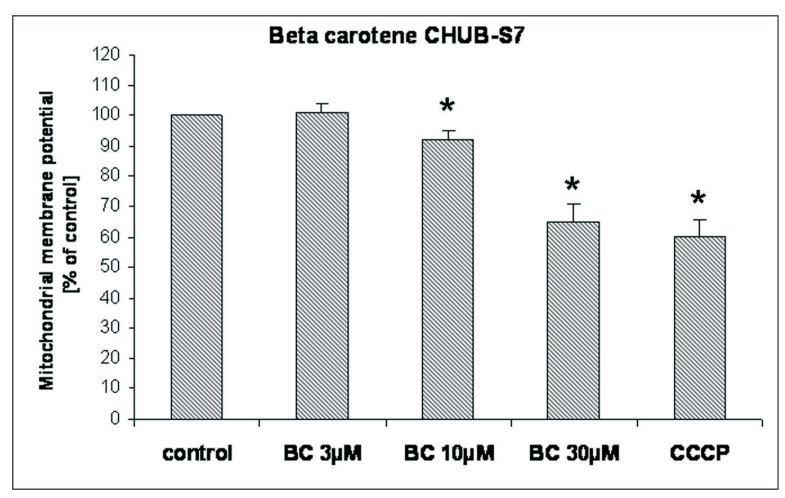

Figure1. Effect of beta-carotene (BC) on mitochondrial membrane potential in Chub-S7 cells incubated with BC $(3,10,30$ $\mu \mathrm{M})$ for $24 \mathrm{~h}$.

Carbonyl cyanide 3-chlorophenylhydrazone (CCCP) was used as positive control. Values are given as $\%$ of control $\pm S$.D. from 5 independent experiments. ${ }^{*} p<0.05$ vs control.

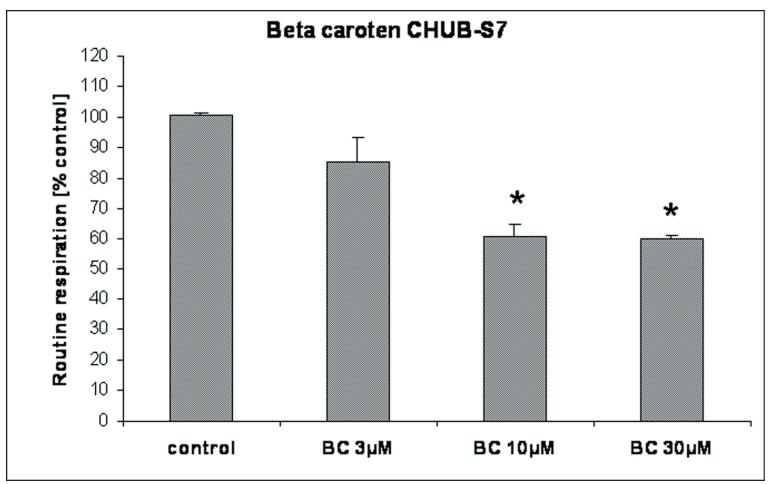

Figure 2. Influence of beta-carotene (BC) on mitochondrial routine respiration.

Cells were incubated with $3,10,30 \mu \mathrm{M}$ of $\mathrm{BC}$ for $24 \mathrm{~h}$. Values are given as $\%$ of control \pm S.D. from 5 independent experiments. ${ }^{*} p<0.05$ vs control.

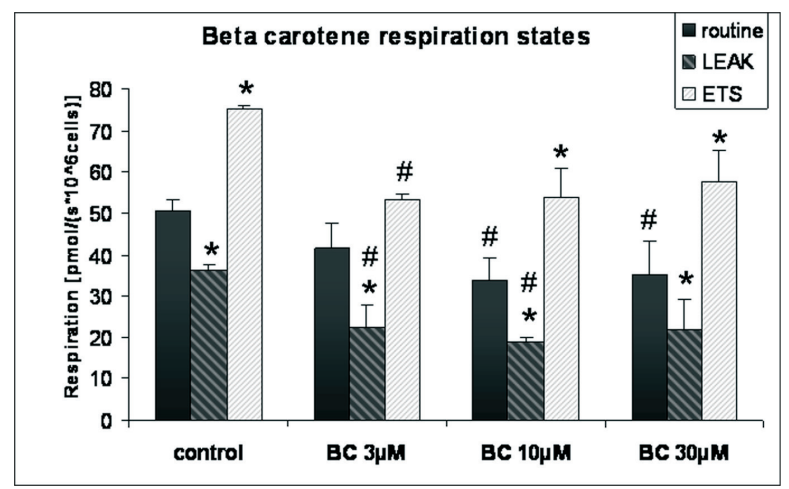

Figure 3. Mitochondrial respiration was analyzed by high-resolution respirometry.

routine, routine respiration; LEAK, the oligomycin (final concentration $2 \mu \mathrm{g} / \mathrm{ml}$ )-inhibited respiration, ETS, electron transport system capacity of uncoupled mitochondria. Values are given as pmol/ $\left(\right.$ s $\times 10^{\circ}$ cells) \pm S.D. from 5 independent experiments. ${ }^{*} p<0.05$ vs routine respiration for each group; $\# p<0.05$ vs control. 


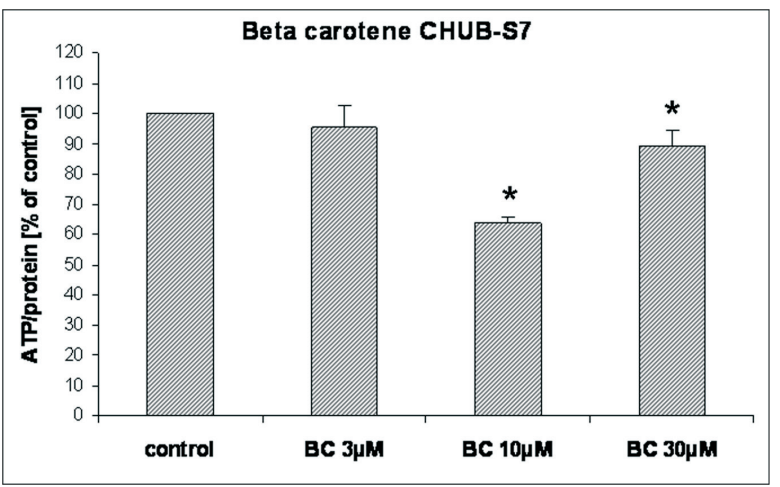

Figure 4. Changes in ATP content in Chub-S7 cells after $24 \mathrm{~h}$ incubation with beta-carotene $(B C)(3,10,30 \mu \mathrm{M})$.

Values are given as $\%$ of control \pm S.D. from 5 independent experiments ${ }^{*} p<0.05$ vs control.

such as the permeability transition pore and release of cytochrome $c$, which has been proposed to trigger apoptosis (Takeyama et al., 2002).

Carotenoid cleavage products - retinal as well as $\beta$-ionone-were demonstrated to increase oxidative stress in isolated rat liver mitochondria by impairing mitochondrial function (Siems et al., 2002). We have demonstrated, that BC decreases mitochondrial routine respiration and reduces the oligomycin-inhibited LEAK respiration, which is caused mainly by compensation for the proton leak after inhibition of ATP synthase. Siems et al. (2002) reported that carotenoid cleavage products strongly inhibit the ADP-induced increase in respiration in a concentration-dependent manner. Impairment of adenine nucleotide translocator may be responsible for the decrease in respiration (Siems et al., 2005). This observation is in disagreement with our results because in our experiments additional we observed decrease $\Delta \Psi \mathrm{m}$, that suggests existence of other mechanism.

Carotenoids accumulating in hepatocytes induce oxidative stress, change activity of manganese superoxide dysmutase, and cause mitochondrial dysfunction, by reduction of ADP-dependent respiration rates as well as depolarization of mitochondrial membranes (Amengual et al., 2011). Carotenoid metabolites strongly inhibit state 3 respiration of rat liver mitochondria (Siems et al., 2009). The decrease of ATP generation in skeletal muscles by the other antioxidant: Vit $\mathrm{C}$ in athletics has been also reported (Gomez-Cabrera et al., 2008).

Thus the metabolic effect of beta-carotene, which is widely used as dietary supplement, is still not completely recognized in different cell types. We conclude that it may impair mitochondrial function of human preadipocytes by decreasing mitochondrial membrane potential, inhibition of mitochondrial respiration and ATP generation. The presented date suggest that potential mechanism of beta-carotene-induced apoptosis could be related with mitochondrial pathway.

\section{Acknowledgements}

This work was Supported by EU FW7 LIPIDOMICNET 202272; K/ZBW/000577.

\section{REFERENCES}

Amengual J, Lobo GP, Golczak M, Li HN, Klimova T, Hoppel CL, Wyss A, Palczewski K, von Lintig J (2011) A mitochondrial enzyme degrades carotenoids and protects against oxidative stress. FASEB J 25: 948-959.

Borutaite V (2010) Mitochondria as decision-markers in cell death. Environ. Mol Mutagen 51: 406-416.

Bournat J, Brown C (2010) Mitochondrial dysfunction in obesity. Curr Opin Endocrinol Diabetes Obes 17: 446-452.

Darimont C, Zbinden I, Avanti O, Leone-Vautravers P, Giusti V, Burckhardt P, Pfeifer AMA, Macé K (2003) Reconstitution of telomerase activity combined with HPV-E7 expression allow human preadipocytes to preserve their differentiation capacity after immortalization. Cell Death Differ 10: 1025-1031.

Dembińska-Kieć A, Polus A, Kieć-Wilk B, Grzybowska J, Mikołajczyk M, Hartwich J, Raźny U, Szumilas K, Banaś A, Bodzioch M, Stachura J, Dyduch G, Laidler P, Zagajewski J, Langmann T, Schmitz $G$ (2005) Proangiogenic activity of beta-carotene is coupled with the activation of endothelial cell chemotaxis. Biochim Biophys Acta 1740: 222-239.

Dulińska J, Gil D, Zagajewski J, Hartwich J, Bodzioch M, DembińskaKieć A, Langmann T, Schmitz G, Laidler P (2005) Different effect of beta-carotene on proliferation of prostate cancer cells. Biochim Biophys Acta 1740: 189-201.

Garedew A, Haffner B, Hütter E, Gnaiger E (2010) An experiment with high-resolution respirometry:Phosphorylation control in cell respiration. Mitochondr Physiol Network 10.04: 1-13.

Gomez-Cabrera MC, Domenech E, Romagnoli M, Arduini A, Borras C, Pallardo FV, Sastre J, Vina J (2008) Oral administration of vitamin $\mathrm{C}$ decreases muscle mitochondrial biogenesis and hampers training-induced adaptations in endurance performance. Am J Clin Nutr 87: 142-149.

Kalariya NM, Ramana KV, Srivastava SK, van Kuijk FJ (2008) Carotenoid derived aldehydes-induced oxidative stress causes apoptotic cell death in human retinal pigment epithelial cells. Exp Eye Res 86: 70-80.

Kieć-Wilk B, Raźny U, Mathers JC, Dembińska-Kieć A (2009) DNA methylation, induced by beta-carotene and arachidonic acid, plays a regulatory role in the pro-angiogenic VEGF-receptor (KDR) gene expression in endothelial cells. I Physiol Pharmacol 60: 49-53.

Kotake-Nara E, Kushir M, Zhang H, Sugawa T, Miyashita K, Nagao A (2001) Carotenoids affect proliferation of human prostate cancer. $J$ Nutr 131: 3303-3306.

Palozza P (1998) Prooxidant actions of carotenoids in biologic systems. Nutr Rev 56: 257-265.

Palozza P, Serini S, Di Nucuolo F, Calviello G (2001) Mitogenic and apoptotic signaling by carotenoids: Involvement of a redox mechanism. IUBMB Life 52: 77-81.

Palozza P, Serini S, Di Nucuolo F, Calviello G (2004) Modulation of apoptotic signaling by carotenoids in cancer cells. Arch Biochem Biophys 430: 104-109.

Ren J, Pulakat L, Whaley-Connell A, Sowers J (2010) Mitochondrial biogenesis in the metabolic syndrome and cardiovascular disease. $J$ Mol Med 88: 993-1001.

Renner K, Amberger A, Konwalinka G, Gnaiger E (2003) Changes of mitochondrial respiration, mitochondrial content and cell size after induction of apoptosis in leukemia cells. Biochim Biophys Acta 1642: 115-123.

Sacha T, Zawada M, Hartwich J, Lach Z, Polus A, Szostek M, Zdziłowska E, Libura M, Bodzioch M, Dembińska-Kieć A, Skotnicki A, Góralczyk R, Wertz K, Riss G, Moele Ch, Langmann T, Schmitz G (2005) The effect of $\beta$-carotene and its derivatives on cytotoxicity, differentiation, proliferative potential and apoptosis on the three human acute leukemia cell lines: U-937, HL-60 and TF-1. Biochimi Biophys Acta 1740: 206-214.

Siems W, Salerno C, Crifò C, Sommerburg O, Wiswedel I (2009) Betacarotene degradation products - formation, toxicity and prevention of toxicity. Forum Nutr 61: 75-86.

Siems W, Wiswedel I, Salerno C, Crifò C, Augustin W, Schild L, Langhans CD, Sommerburg O (2005) Beta-carotene breakdown products may impair mitochondrial functions - potential side effects of high-dose beta-carotene supplementation. J Nutr Biochem 16: 385-397.

Siems W, Sommerburg O, Schild L, Augustin W, Langhans C-L, Wiswedel I (2002) $\beta$-Carotene cleavage products induce oxidative stress in vitro by impairing mitochondrial respiration. FASEB J 16: 1289-1291.

Takeyama N, Miki S, Harakawa A, Tanaka T (2002) Role of the mitochondrial permeability transition and cytochrome $C$ release in hydrogen peroxide-induced apoptosis. Exp Cell Res 274: 16-24.

Wang T, Si Y, Shirihai OS, Si H, Schultz V, Corkey RF, Hu L, Deeney J, Guo W, Corkey BE (2010) Respiration in adipocytes is inhibited by reactive oxygen species. Obesity 18: 1493-1502. 